\title{
Local infusion of low, but not high, doses of alcohol into the anterior ventral tegmental area causes release of accumbal dopamine
}

\author{
Elisabet Jerlhag*, Jörgen A. Engel \\ Section for Pharmacology, Institute of Neuroscience and Physiology, The Sahlgrenska Academy at the University of Gothenburg, \\ Gothenburg, Sweden \\ Email: "elisabet.jerlhag@pharm.gu.se
}

Received 22 November 2013; revised 18 December 2013; accepted 26 December 2013

Copyright (C 2014 Elisabet Jerlhag, Jörgen A. Engel. This is an open access article distributed under the Creative Commons Attribution License, which permits unrestricted use, distribution, and reproduction in any medium, provided the original work is properly cited. In accordance of the Creative Commons Attribution License all Copyrights (C) 2014 are reserved for SCIRP and the owner of the intellectual property Elisabet Jerlhag, Jörgen A. Engel. All Copyright (C 2014 are guarded by law and by SCIRP as a guardian.

\section{ABSTRACT}

The mesolimbic dopamine system consisting of dopaminergic neurons projecting from the ventral tegmental area (VTA) to the nucleus accumbens (N.Acc.) mediates the reinforcing effects of addictive drugs including alcohol. Given that VTA is a heterogeneous area and that alcohol, in rather low doses, interacts directly with ligand-gated ion channels, we hypothesised that low, rather than high, doses of alcohol into the VTA activate the mesolimbic dopamine system and that alcohol may have different effects in the anterior and posterior parts of the VTA. The present study was undertaken to investigate this hypothesis. The present series of experiment show that infusion of a low dose of alcohol ( $20 \mathrm{mM})$ into the anterior, but not posterior, part of the VTA increases accumbal dopamine release in rats. In addition, higher doses of alcohol (100 or $300 \mathrm{mM})$ into the anterior or posterior part of the VTA do not affect the release of dopamine in the N.Acc., suggesting that low doses of alcohol can activate the mesolimbic dopamine system via mechanisms in the VTA. These data contribute to understanding the neuronal mechanisms underlying the dependence-producing properties of alcohol and could tentatively contribute to that new treatment strategies for alcohol use disorder can be developed.

\section{KEYWORDS}

Alcohol; Ventral Tegmental Area; Nucleus

Accumbens; Dopamine; Rats

${ }^{*}$ Corresponding author.

\section{INTRODUCTION}

The mesolimbic dopamine system, a common neurochemical dominator of the reward system, consists of dopaminergic neurons projecting from the ventral tegmental area (VTA) to the nucleus accumbens (N.Acc.) [1-4]. The first evidence demonstrating a causal relationship between alcohol-induced stimulation of behaviour and dopamine activity was that a catecholaminesynthesis inhibitor antagonizes the alcohol-induced euphoria in humans [5] and locomotor stimulation in rats [6]. Since then, microdialysis studies have shown that addictive drugs, including alcohol, as well as natural rewards, such as food, activate this reward link causing a release of accumbal dopamine in vivo in rats (see e.g. [7-12]). Additionally, voluntary alcohol consumption increases the extracellular concentrations of dopamine in rats [13-15] and in humans [16]. The accumbal dopamine release mediates the reinforcing effects of addictive drugs and palatable foods (for review see [17-19]), and a dysfunction in this system may cause addictive behaviours such as alcohol dependence (for review see [20]). Moreover, a role for accumbal dopamine in incentive salience, a motivated behaviour for reward has been implied (for review see [21]).

The neuronal mechanisms underlying the dependenceproducing properties of drugs of abuse, such as increased accumbal dopamine release, are not clearly understood and need to be further elucidated. To date, both VTA and $\mathrm{N}$.Acc. have been shown to have important roles for the ability of alcohol to activate the mesolimbic dopamine system. Thus, infusing alcohol into the N.Acc. causes a release of dopamine in the N.Acc. [22-26] and intravenous administration of low doses of alcohol produces a increase of dose dependent in firing rate of dopamine 
neurons in the VTA projecting to N.Acc. [27]. Given that VTA is a heterogeneous area and that alcohol, in rather low doses, interacts directly with ligand-gated ion channels (for review see $[28,29]$ ), it was hypothesised that low, rather than high, doses of alcohol into the VTA indirectly activate the mesolimbic dopamine system and that alcohol may have different effects in the anterior and posterior parts of the VTA. The present series of experiments were undertaken to directly test this hypothesis by investigating the effect of alcohol, low or high doses, infused directly into the anterior or posterior part of the VTA on accumbal dopamine release in freely moving rat by using in vivo microdialysis.

\section{MATERIALS AND METHODS}

\subsection{Animals}

Adult post-pubertal age-matched male Wistar rats (250 300 g body weight; Charles River, Sulzfeld, Germany) were used as asimilar study is documented in this strain (Larsson et al., 2005). All rats were maintained at $20^{\circ} \mathrm{C}$ with 50\% humidity and a 12/12 hour light/dark cycle (lights on at seven a.m.) and were allowed to habituate to the animal facilities for at least one week before initiation of the experiment. Tap water and food (Normal chow; Harlan Teklad, Norfolk, England) were supplied ad libitum, except during the microdialysis experiment. The Ethics Committee for Animal Experiments in Gothenburg, Sweden has approved the experiments.

\subsection{Drugs}

Alcohol (VWR International, Stockholm, Sweden) was dissolved in Ringer solution $(140 \mathrm{mM} \mathrm{NaCl}, 1.2 \mathrm{mM}$ $\mathrm{CaCl}_{2}, 3.0 \mathrm{mM} \mathrm{KCl}$ and $1.0 \mathrm{MgCl}_{2}$ (Merck KGaA, Darmstadt, Germany)) to the correct concentrations (20, $100,300 \mathrm{mM}$ ) and was administered locally into the VTA via reversed microdialysis. All drug challenges were part of a balanced design with regard to both the treatment order and the number of subjects per treatment. Each rat was only included in one microdialysis experiment.

\subsection{In Vivo Microdialysis}

For measurements of extracellular levels of dopamine in the N.Acc. (that reflects the release of the neurotransmitter) rats were implanted unilaterally with microdialysis probes positioned in the N.Acc.. For local infusion of alcohol or vehicle rats were also implanted with a microdialysis probe ipsilaterlly into the VTA. Only rats with correct probe positions in the VTA as well as N.Acc. were included in the statistical analysis. The surgery was performed as described thoroughly elsewhere [14]. In brief, the rats were anesthetized with isofluran (Isofluran Baxter; Univentor 400 Anaesthesia Unit, Univentor Ltd.,
Zejtun, Malta), placed in a stereotaxic frame (David Kopf Instruments; Tujunga, CA, USA) and kept on a heating pad to prevent hypothermia. The skull bone was exposed and two holes for the probes and one for the anchoring screw were drilled. The probes were randomly alternated to either the left or right side and were always positioned ipsilateral. The following coordinates were used for N.Acc.: $1.85 \mathrm{~mm}$ anterior to the bregma, \pm 1.0 $\mathrm{mm}$ lateral to the midline and $7.8 \mathrm{~mm}$ below the surface of the brain surface, and for VTA: $5.00 \mathrm{~mm}$ (anterior part of VTA) or $6.0 \mathrm{~mm}$ (posterior part of the VTA) posterior to the bregma, $\pm 0.6 \mathrm{~mm}$ lateral to the midline and 8.5 $\mathrm{mm}$ below the surface of the brain surface [30]. The choice of coordinates for anterior and posterior VTA was based on previous studies with local administrations of alcohol into the VTA $[22,31]$ in rats. The probes were attached to the skull with dental cement (Agntho's AB, Lidingö, Sweden). The exposed tip of the dialysis membrane (20,000 kDa cut off with an o.d./i.d. of 310/220 $\mu \mathrm{m}$, HOSPAL, Gambro, Lund, Sweden) of the probe was $2 \mathrm{~mm}$ for N.Acc. and $1.5 \mathrm{~mm}$ for VTA. All probes were surgically implanted two days prior to the experiment. After surgery the rats were kept in individual cages (Macrolon III). All microdialysis experiments were conducted during the light phase.

The microdialysis technique enables measurements of neurotransmitters in awake, freely moving animals. On the day of the experiment the probe was connected to a microperfusion pump (U-864 Syringe Pump; AgnThós $\mathrm{AB}$ ) and perfused with Ringer solution at a rate of 1.6 $\mu \mathrm{l} /$ minute. After one hour of habituation to the microdialysis set-up, perfusion samples were collected every 20 minutes.

In the first series of experiments the effect of two higher doses of alcohol (100 mM or $300 \mathrm{mM}$ ) compared to vehicle (Ringer's solution) on accumbal dopamine in rats were investigated. The baseline dopamine level was defined as the average of three consecutive samples before the drug challenge, and the increase in dopamine was calculated as the percent increase from baseline. After the baseline samples, rats were locally perfused with either alcohol $(100 \mathrm{mM}$ or $300 \mathrm{mM})$ or vehicle (Ringer's solution) locally into the anterior $(-5.0 \mathrm{~mm})$ or posterior $(-6.0 \mathrm{~mm})$ part of the VTA and the six subsequent samples were collected and analyzed. Alcohol or vehicle was perfused until termination of the experiment at a rate of $1.6 \mu \mathrm{l} /$ minute.

In subsequent experiments, in different rats, the effects of a low dose of alcohol $(20 \mathrm{mM})$ compared to vehicle (Ringer's solution) on accumbal dopamine in rats were investigated. The baseline dopamine level was defined as the average of three consecutive samples before the drug challenge, and the increase in dopamine was calculated 
as the percent increase from baseline. After the baseline samples, rats were locally perfused with either alcohol (20 $\mathrm{mM}$ ) or vehicle (Ringer's solution) locally into the anterior $(-5.0 \mathrm{~mm})$ or posterior $(-6.0 \mathrm{~mm})$ part of the VTA. Alcohol or vehicle was administered until termination of the experiment. Six subsequent samples were collected and analyzed. Alcohol or vehicle was perfused until termination of the experiment at a rate of 1.6 $\mu \mathrm{l} / \mathrm{minute}$.

In both these series of experiments Ringer's solution was switched to alcohol solution. This was done by changing the syringe and inlet tube into the swivel, which allows a rapid change of solution into the VTA.

\subsection{Verification of Probe and Cannula Placement}

After the microdialysis experiments were completed, the location of the probes was verified. The rats were decapitated, probes were perfused with pontamine sky blue $6 \mathrm{BX}$ to facilitate probe localization, and the brains were mounted on a vibroslice device (752M Vibroslice; Campden Instruments Ltd., Loughborough, UK). The brains were cut in $50 \mu \mathrm{m}$ sections and the location of the probe was determined by gross observation using light microscopy. The exact position of the probes was verified [30].

\subsection{Dopamine Analysis}

The dopamine levels in the dialysates were determined by means of HPLC with electrochemical detection (HPLC-EC). The analysis was performed as described thoroughly elsewhere [14,32]. In brief, a pump (Gyncotec P580A; Kovalent AB), an ion exchange column $(2.0 \times 100 \mathrm{~mm}$, Prodigy $3 \mu \mathrm{m} \mathrm{SA}$; Skandinaviska GeneTec AB; Kungsbacka, Sweden) and a detector (Antec Decade; Antec Leyden, Zoeterwoude, The Netherlands) equipped with a VT-03 flow cell (Antec Leyden) was used. The mobile phase ( $\mathrm{pH} 5.6$ ), consisting of sulfonic acid $10 \mathrm{mM}$, citric acid $200 \mathrm{mM}$, sodium citrate $200 \mathrm{mM}$, 10\% EDTA, 30\% MeOH, was vacuum filtered by using a $0.2 \mu \mathrm{m}$ membrane filter (GH Polypro; PALL Gelman Laboratory, Lund, Sweden). The mobile phase was delivered at a flow rate of $0.2 \mathrm{ml} / \mathrm{min}$ passing a degasser (Kovalent $\mathrm{AB}$ ), and the analyte was oxidized at $+0.4 \mathrm{~V}$.

\subsection{Statistical Analyses}

All microdialysis experiments were evaluated by a twoway analysis of variance (ANOVA) followed by Bonferroni post-hoc test for comparisons between different treatments and specifically at given time points. Data are presented as mean \pm SEM. A probability value of $P<$ 0.0167 was considered as statistically significant.

\section{RESULTS}

Effects of Local Administration of Alcohol into the VTA on Accumbal Dopamine Release in Rats

Here we initially showed that local infusion of alcohol (100 $\mathrm{mM}$ or $300 \mathrm{mM})$, either into the anterior $(-5.0 \mathrm{~mm})$ or posterior $(-6.00 \mathrm{~mm})$ part of the VTA, did not affect the extracellular levels of dopamine in N.Acc. in rats (data not shown) (treatment $\mathrm{F}(5,35)=1.43, P=0.2375$; time $\mathrm{F}(8280)=2.76, P=0.0060$; treatment $\times$ time interaction $\mathrm{F}(8280)=1.68, P=0.0092)$. No statistically difference was observed between alcohol or vehicle (Ringer) perfusion into the anterior or posterior part of the VTA.

Subsequently we showed that a low dose of alcohol $(20 \mathrm{mM})$ into the anterior $(-5.0 \mathrm{~mm})$, but not posterior $(-6.0 \mathrm{~mm})$ part of the VTA, increased the levels of dopamine in N.Acc. in rats (Figure 1 ).

Alcohol (20 mM) to the anterior, but not posterior, part of the VTA increased accumbal dopamine release relative to vehicle treatment $(P=0.0002$ and $P=0.2013$ respectively) (treatment $\mathrm{F}(3,37)=7.577, P=0.0005$; time $\mathrm{F}(8296)=2.804, P=0.0052$; treatment $\times$ time interaction $\mathrm{F}(8296)=3.511, P<0.0001 ; \mathrm{n}=8$ for vehicle -5.0 and vehicle $-6.0, n=11$ for alcohol -5.0 and $n=14$ for alcohol -6.0). This increase was evident at time interval 40 minutes $(P=0.0034), 60$ minutes $(P<0.0001)$ and 80 minutes $(P=0.0049$ ) (for alcohol-5.0 versus vehicle-5.0). No statistical significant difference was observed between vehicle (Ringer) perfusion into the anterior or posterior part of the VTA $(P=0.7558)$.

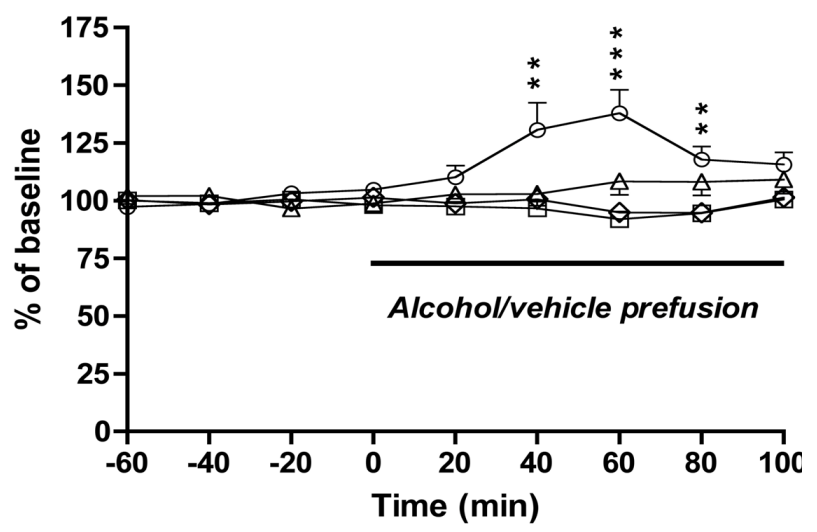

Figure 1. Effects of local administration of alcohol into the ventral tegmental area on accumbal dopamine release in rats. A low dose of alcohol $(20 \mathrm{mM})$ into the anterior $(-5.0$ $\mathrm{mm})$, but not posterior $(-6.0 \mathrm{~mm})$ part of the VTA, increased the levels of dopamine in N.Acc. in rats. No significant difference was observed between the vehicle treatment into the anterior $(-5.0 \mathrm{~mm})$ posterior part of VTA $(-6.0 \mathrm{~mm})$ ( $\mathrm{n}=\mathbf{8}$ for vehicle $-5.0 \mathrm{~mm}$ (square), $\mathrm{n}=\mathbf{8}$ for vehicle -6.0 mm (rhomb), $n=11$ for alcohol $-5.0 \mathrm{~mm}$ (circle) and $\mathrm{n}=14$ for alcohol $-6.0 \mathrm{~mm}$ (triangle). All values represent mean \pm SEM $\left({ }^{* * *} P<0.001\right.$ and $\left.{ }^{* *} P<0.01\right)$. 
It should be emphasized that only rats with correct probe positions in the VTA, i.e. alcohol/vehicle administration, as well as N.Acc., i.e. dopamine measurements, were included in the statistical analysis.

\section{DISCUSSION}

The present series of experiments show that local perfusion of a low dose of alcohol into the anterior, but not posterior, part of the VTA increases accumbal dopamine releasein rats. Moreover, high doses of alcohol into either part of the VTA, does not affect the extracellular concentrations of dopamine in N.Acc.; suggesting that low, and not high, doses of alcohol activate the mesolimbic dopamine system via mechanisms in the anterior part of the VTA.

VTA is a heterogeneous brain structure and the anterior versus the posterior part of the VTA differ in dopaminergic cell morphology, topography of their efferent projections, and presumably in function (for review see [33]). Supportively, caudoventral dopamine neurons are more active during the rat's active dark period, whereas rostrodorsal DA neurons are active during the light period [34]. Given that we here showed that low dose of alcohol in the anterior, but not posterior, part of the VTA increases accumbal dopamine release and that rats self-administer nicotine in the anterior part of the VTA [35], an important role for anterior VTA in drug reward may be suggested. However, dopamine neurons in the posterior part of the VTA may also be involved in the reinforcing properties of addictive drugs. Thus rats voluntarily self-administer alcohol, as well ascholinergic agonists, muscimol or acetaldehyde, into the posterior, but not anterior, part of the VTA [36-41]. Moreover, co-administration of alcohol with a dopamine $\mathrm{D}_{2}$ receptor agonist into the posterior, but not anterior, VTA extinguished the maintenance of alcohol self-infusion [40].

The present data confirm previous results showing that high doses of alcohol, neither into the anterior nor posterior part of the VTA, affect the extracellular levels of dopamine in the N.Acc. in Wistar [22] and in alcohol preferring AA [31] rats. Alcohol, in rather low doses, activates ligand-gated ion channels including nicotinic acetylcholine, and $\mathrm{GABA}_{\mathrm{A}}$ receptors (for review see $[28,29])$. Previously, alcohol-induced reward, as measured by alcohol-induced locomotor stimulation, accumbal dopamine release, and alcohol intake were shown to be mediated via nicotinic acetylcholine receptors, especially those located in the VTA $[10,12,13,23,42-47]$. Additionally, anterior ventral tegmental acetylcholine receptors mediate the ability of accumbal alcohol to increase dopamine in the N.Acc. [22]. GABA on the other hand, mediates the sedative, anxiolytic and muscle relaxant effects of alcohol [48] and local administration of a $\mathrm{GABA}_{\mathrm{A}}$ antagonist into the anterior part of VTA in- creases accumbal dopamine [49]. It may therefore be suggested that low doses of alcohol into the anterior part of the VTA activate nicotinic acetylcholine receptors, which causes an activation of the mesolimbic dopamine system, i.e. accumbal dopamine release. Higher doses of alcohol into the VTA may on the other hand activate $\mathrm{GABA}_{\mathrm{A}}$ receptors and therefore not cause a release of dopamine in N.Acc.. However this needs to be further elucidated.

Our present findings are in consensus with previous suggestions on alcohol interfering with VTA-dopamine neurons. Thus, a role for the VTA was initially suggested since intravenous administration of low doses of alcohol produces a dose dependent increase in firing rate of dopamine neurons in the VTA projecting to N.Acc. in vivo [27] and in vitro [50-54]. Furthermore, alcohol increases the firing of acutely dissociated VTA dopamine neurons [53] and that this effect persists albeit blockade of synaptic transmission by high magnesium/low calcium [50], suggesting that alcohol activates dopamine neurons directly in absence of input from surrounding neurons. However, additional sites of actions are most likely since alcohol is a small hydrophilic/lipophilic molecule and following alcohol consumption alcohol may in all probability effects several brain regions. Indeed, reverse microdialysis of alcohol into the N.Acc. has previously been shown to increases accumbal dopamine [22-26] involving nicotinic acetylcholine receptors in the anterior part of the VTA [22]. Growing evidence has collectively implied that the cholinergic-dopaminergic reward link, encompassing the cholinergic afferent projection from the laterodorsal tegmental area (LDTg) onto the VTA dopamine cells together with the mesolimbic dopamine neurons from the VTA to N.Acc., mediates the reinforcing properties of natural as well as artificial rewards $[3,55]$ (for review see [28,29]). Further support for an important role for nicotinic receptor in the VTA is given by the findings that rats self-administer nicotine in the anterior part of the VTA [35]. The data showing that alcohol intake in high alcohol-preferring rats causes a concomitant increase in ventral tegmental acetylcholine and accumbal dopamine [14], further strengthen an important role of the cholinergic-dopaminergic reward link and indirectly imply that alcohol also may have local effects in the LDTg. Although, other sites of action for alcohol should also be taken into consideration.

\section{CONCLUSION}

In summary, the present study shows that low, but not high, dose of alcohol activates the mesolimbic dopamine system via the anterior, but not posterior, part of the VTA. These data contribute to understanding the neuronal mechanisms underlying the dependence-producing properties of drugs of abuse, such as increased accumbal do- 
pamine release. This additional knowledge in how alcohol activates the mesolimbic dopamine system could tentatively contribute to that new treatment strategies for alcohol use disorder can be developed.

\section{ACKNOWLEDGEMENTS}

Gun Andersson and Kenn Johannessen are gratefully acknowledged for expert and valuable technical assistance. Supported by grants from the Swedish Research Council (grant no. K2006-21X-04247-33-3 and 2009-2782), The Swedish brain foundation, LUA/ALF (grant no. 148251) from the Sahlgrenska University Hospital, Alcohol research council of the Swedish alcohol retailing monopoly and the foundations of Adlerbertska, Fredrik and Ingrid Thuring, Tore Nilsson, Längmanska, Torsten and Ragnar Söderberg, Wilhelm and Martina Lundgren, Knut and Alice Wallenberg, Magnus Bergvall, Anérs, Jeansons, Åke Wiberg, and the Swedish Society of Medicine.

\section{REFERENCES}

[1] Engel, J.A. (1977) Neurochemical aspects of the europhoria induced by dependence-producing drugs, Amsterdam. Excerpta Medica, 16-22.

[2] Koob, G.F. (1992) Drugs of abuse: Anatomy, pharmacology and function of reward pathways. Trends in Pharmacological Sciences, 13, 177-184. http://dx.doi.org/10.1016/0165-6147(92)90060-J

[3] Wise, R.A. and Rompre, P.P. (1989) Brain dopamine and reward. Annual Review of Psychology, 40, 191-225. http://dx.doi.org/10.1146/annurev.ps.40.020189.001203

[4] Spanagel, R. and Weiss, F. (1999) The dopamine hypothesis of reward: Past and current status. Trends in Neurosciences, 22, 521-527.

http://dx.doi.org/10.1016/S0166-2236(99)01447-2

[5] Ahlenius, S., Carlsson, A., Engel, J., Svensson, T. and Sodersten, P. (1973) Antagonism by alpha methyltyrosine of the ethanol-induced stimulation and euphoria in man. Clinical Pharmacology \& Therapeutics, 14, 586-591.

[6] Engel, J., Strombom, U., Svensson, T.H. and Waldeck, B. (1974) Suppression by alpha-methyltyrosine of ethanolinduced locomotor stimulation: Partial reversal by L-dopa. Psychopharmacologia, 37, 275-279.

http://dx.doi.org/10.1007/BF00421541

[7] Di Chiara, G. and Imperato, A. (1986) Preferential stimulation of dopamine release in the nucleus accumbens by opiates, alcohol, and barbiturates: Studies with transcerebral dialysis in freely moving rats. Annals of the New York Academy of Sciences, 473, 367-381. http://dx.doi.org/10.1111/j.1749-6632.1986.tb23629.x

[8] Engel, J.A., Fahlke, C., Hulthe, P., Hard, E., Johannessen, K., et al. (1988) Biochemical and behavioral evidence for an interaction between ethanol and calcium channel antagonists. Journal of Neural Transmission, 74, 181-193. http://dx.doi.org/10.1007/BF01244784

[9] Imperato, A. and Di Chiara, G. (1986) Preferential stimulation of dopamine release in the nucleus accumbens of freely moving rats by ethanol. Journal of Pharmacology and Experimental Therapeutics, 239, 219-228.

[10] Larsson, A., Jerlhag, E., Svensson, L., Soderpalm, B. and Engel, J.A. (2004) Is an alpha-conotoxin MII-sensitive mechanism involved in the neurochemical, stimulatory, and rewarding effects of ethanol? Alcohol, 34, 239-250. http://dx.doi.org/10.1016/j.alcohol.2004.10.002

[11] Larsson, A., Svensson, L., Soderpalm, B. and Engel, J.A. (2002) Role of different nicotinic acetylcholine receptors in mediating behavioral and neurochemical effects of ethanol in mice. Alcohol, 28, 157-167. http://dx.doi.org/10.1016/S0741-8329(02)00244-6

[12] Blomqvist, O., Engel, J.A., Nissbrandt, H. and Soderpalm, B. (1993) The mesolimbic dopamine-activating properties of ethanol are antagonized by mecamylamine. European Journal of Pharmacology, 249, 207-213. http://dx.doi.org/10.1016/0014-2999(93)90434-J

[13] Ericson, M., Blomqvist, O., Engel, J.A. and Soderpalm, B. (1998) Voluntary ethanol intake in the rat and the associated accumbal dopamine overflow are blocked by ventral tegmental mecamylamine. European Journal of Pharmacology, 358, 189-196.

http://dx.doi.org/10.1016/S0014-2999(98)00602-5

[14] Larsson, A., Edstrom, L., Svensson, L., Soderpalm, B. and Engel, J.A. (2005) Voluntary ethanol intake increases extracellular acetylcholine levels in the ventral tegmental area in the rat. Alcohol and Alcoholism, 40, 349-358. http://dx.doi.org/10.1093/alcalc/agh180

[15] Doyon, W.M., York, J.L., Diaz, L.M., Samson, H.H., Czachowski, C.L., et al. (2003) Dopamine activity in the nucleus accumbens during consummatory phases of oral ethanol self-administration. Alcoholism: Clinical and Experimental Research, 27, 1573-1582. http://dx.doi.org/10.1097/01.ALC.0000089959.66222.B8

[16] Boileau, I., Assaad, J.M., Pihl, R.O., Benkelfat, C., Leyton, M., et al. (2003) Alcohol promotes dopamine release in the human nucleus accumbens. Synapse, 49, 226-231. http://dx.doi.org/10.1002/syn.10226

[17] Dickson, S.L., Egecioglu, E., Landgren, S., Skibicka, K.P., Engel, J.A., et al. (2011) The role of the central ghrelin system in reward from food and chemical drugs. Molecular and Cellular Endocrinology, 340, 80-87. http://dx.doi.org/10.1016/j.mce.2011.02.017

[18] Egecioglu, E., Skibicka, K.P., Hansson, C., AlvarezCrespo, M., Friberg, P.A., et al. (2011) Hedonic and incentive signals for body weight control. Reviews in Endocrine and Metabolic Disorders, 12, 141-151. http://dx.doi.org/10.1007/s11154-011-9166-4

[19] Soderpalm, B. and Ericson, M. (2013) Neurocircuitry involved in the development of alcohol addiction: The dopamine system and its access points. Current Topics in Behavioral Neurosciences, 13, 127-161. http://dx.doi.org/10.1007/7854_2011_170

[20] Wang, G.J., Volkow, N.D., Thanos, P.K. and Fowler, J.S. (2004) Similarity between obesity and drug addiction as assessed by neurofunctional imaging: A concept review. Journal of Addictive Diseases, 23, 39-53. http://dx.doi.org/10.1300/J069v23n03_04

[21] Robinson, T.E. and Berridge, K.C. (1993) The neural basis of drug craving: An incentive-sensitization theory 
of addiction. Brain Research Reviews, 18, 247-291. http://dx.doi.org/10.1016/0165-0173(93)90013-P

[22] Ericson, M., Lof, E., Stomberg, R., Chau, P. and Soderpalm, B. (2008) Nicotinic acetylcholine receptors in the anterior, but not posterior, ventral tegmental area mediate ethanol-induced elevation of accumbal dopamine levels. Journal of Pharmacology and Experimental Therapeutics, 326, 76-82. http://dx.doi.org/10.1124/jpet.108.137489

[23] Ericson, M., Molander, A., Lof, E., Engel, J.A. and Soderpalm, B. (2003) Ethanol elevates accumbal dopamine levels via indirect activation of ventral tegmental nicotinic acetylcholine receptors. European Journal of Pharmacology, 467, 85-93.

http://dx.doi.org/10.1016/S0014-2999(03)01564-4

[24] Lof, E., Olausson, P., deBejczy, A., Stomberg, R., McIntosh, J.M., et al. (2007) Nicotinic acetylcholine receptors in the ventral tegmental area mediate the dopamine activating and reinforcing properties of ethanol cues. Psychopharmacology (Berl), 195, 333-343. http://dx.doi.org/10.1007/s00213-007-0899-4

[25] Wozniak, K.M. and Linnoila, M. (1992) Recent advances in pharmacological research on alcohol. Possible relations with cocaine. Recent Developments in Alcoholism, 10, 235-272. http://dx.doi.org/10.1007/978-1-4899-1648-8 12

[26] Yoshimoto, K., McBride, W.J., Lumeng, L. and Li, T.K. (1992) Alcohol stimulates the release of dopamine and serotonin in the nucleus accumbens. Alcohol, 9, 17-22. http://dx.doi.org/10.1016/0741-8329(92)90004-T

[27] Gessa, G.L., Muntoni, F., Collu, M., Vargiu, L. and Mereu, G. (1985) Low doses of ethanol activate dopaminergic neurons in the ventral tegmental area. Brain Research, 348, 201-203.

http://dx.doi.org/10.1016/0006-8993(85)90381-6

[28] Larsson, A. and Engel, J.A. (2004) Neurochemical and behavioral studies on ethanol and nicotine interactions. Neuroscience and Biobehavioral Reviews, 27, 713-720. http://dx.doi.org/10.1016/j.neubiorev.2003.11.010

[29] Lovinger, D.M. (1997) Alcohols and neurotransmitter gated ion channels: Past, present and future. NaunynSchmiedeberg's Archives of Pharmacology, 356, 267-282. http://dx.doi.org/10.1007/PL00005051

[30] Paxinos, G. and Watson, C. (1998) The brain stereotaxic coordinates. Academic Press, New York, Figure 11 and 44.

[31] Tuomainen, P., Patsenka, A., Hyytia, P., Grinevich, V. and Kiianmaa, K. (2003) Extracellular levels of dopamine in the nucleus accumbens in AA and ANA rats after reverse microdialysis of ethanol into the nucleus accumbens or ventral tegmental area. Alcohol, 29, 117-124. http://dx.doi.org/10.1016/S0741-8329(03)00017-X

[32] Jerlhag, E., Grotli, M., Luthman, K., Svensson, L. and Engel, J.A. (2006) Role of the subunit composition of central nicotinic acetylcholine receptors for the stimulatory and dopamine-enhancing effects of ethanol. Alcohol and Alcoholism, 41, 486-493. http://dx.doi.org/10.1093/alcalc/agl049

[33] Ikemoto, S. (2007) Dopamine reward circuitry: Two projection systems from the ventral midbrain to the nucleus accumbens-olfactory tubercle complex. Brain Research Reviews, 56, 27-78.

http://dx.doi.org/10.1016/j.brainresrev.2007.05.004

[34] Luo, A.H., Georges, F.E. and Aston-Jones, G.S. (2008) Novel neurons in ventral tegmental area fire selectively during the active phase of the diurnal cycle. European Journal of Neuroscience, 27, 408-422. http://dx.doi.org/10.1111/j.1460-9568.2007.05985.x

[35] Ikemoto, S., Qin, M. and Liu, Z.H. (2006) Primary reinforcing effects of nicotine are triggered from multiple regions both inside and outside the ventral tegmental area. The Journal of Neuroscience, 26, 723-730. http://dx.doi.org/10.1523/JNEUROSCI.4542-05.2006

[36] Gatto, G.J., McBride, W.J., Murphy, J.M., Lumeng, L. and Li, T.K. (1994) Ethanol self-infusion into the ventral tegmental area by alcohol-preferring rats. Alcohol, 11, 557-564. http://dx.doi.org/10.1016/0741-8329(94)90083$\underline{3}$

[37] Ikemoto, S., Murphy, J.M. and McBride, W.J. (1998) Regional differences within the rat ventral tegmental area for muscimol self-infusions. Pharmacology Biochemistry and Behavior, 61, 87-92. http://dx.doi.org/10.1016/S0091-3057(98)00086-0

[38] Ikemoto, S. and Wise, R.A. (2002) Rewarding effects of the cholinergic agents carbachol and neostigmine in the posterior ventral tegmental area. Journal of Neuroscience, 22, 9895-9904.

[39] Rodd, Z.A., Bell, R.L., Zhang, Y., Murphy, J.M., Goldstein, A., Zaffaroni, A., Li, T.K. and McBride, W.J. (2005) Regional heterogeneity for the intracranial self-administration of ethanol and acetaldehyde within the ventral tegmental area of alcohol-preferring $(\mathrm{P})$ rats: Involvement of dopamine and serotonin. Neuropsychopharmacology, 30, 330-338. http://dx.doi.org/10.1038/sj.npp.1300561

[40] Rodd, Z.A., Melendez, R.I., Bell, R.L., Kuc, K.A., Zhang, Y., Murphy, J.M. and McBride, W.J. (2004) Intracranial self-administration of ethanol within the ventral tegmental area of male Wistar rats: Evidence for involvement of dopamine neurons. Journal of Neuroscience, 24, 1050-1057. http://dx.doi.org/10.1523/JNEUROSCI.1319-03.2004

[41] Rodd-Henricks, Z.A., McKinzie, D.L., Crile, R.S., Murphy, J.M. and McBride, W.J. (2000) Regional heterogeneity for the intracranial self-administration of ethanol within the ventral tegmental area of female Wistar rats. Psychopharmacology, 149, 217-224. http://dx.doi.org/10.1007/s002139900347

[42] Blomqvist, O., Ericson, M., Engel, J.A. and Soderpalm, B. (1997) Accumbal dopamine overflow after ethanol: Localization of the antagonizing effect of mecamylamine. European Journal of Pharmacology, 334, 149-156. http://dx.doi.org/10.1016/S0014-2999(97)01220-X

[43] Blomqvist, O., Ericson, M., Johnson, D.H., Engel, J.A. and Soderpalm, B. (1996) Voluntary ethanol intake in the rat: Effects of nicotinic acetylcholine receptor blockade or subchronic nicotine treatment. European Journal of Pharmacology, 314, 257-267. http://dx.doi.org/10.1016/S0014-2999(96)00583-3

[44] Blomqvist, O., Soderpalm, B. and Engel, J.A. (1992) Ethanol-induced locomotor activity: Involvement of central ni- 
cotinic acetylcholine receptors? Brain Research Bulletin, 29, 173-178.

http://dx.doi.org/10.1016/0361-9230(92)90023-Q

[45] Le, A.D., Corrigall, W.A., Watchus, J., Harding, S., Juzytsch, W. and Li, T.K. (2000) Involvement of nicotinic receptors in alcohol self-administration. Alcoholism: Clinical and Experimental Research, 24, 155-163. http://dx.doi.org/10.1111/j.1530-0277.2000.tb04585.x

[46] Nadal, R., Chappell, A.M. and Samson, H.H. (1998) Effects of nicotine and mecamylamine microinjections into the nucleus accumbens on ethanol and sucrose self-administration. Alcoholism: Clinical and Experimental Research, 22, 1190-1198. http://dx.doi.org/10.1111/j.1530-0277.1998.tb03898.x

[47] Tizabi, Y., Copeland Jr., R.L., Louis, V.A. and Taylor, R.E. (2002) Effects of combined systemic alcohol and central nicotine administration into ventral tegmental area on dopamine release in the nucleus accumbens. Alcoholism: Clinical and Experimental Research, 26, 394-399. http://dx.doi.org/10.1111/j.1530-0277.2002.tb02551.x

[48] Liljequist, S. and Engel, J. (1982) Effects of GABAergic agonists and antagonists on various ethanol-induced behavioral changes. Psychopharmacology, 78, 71-75. http://dx.doi.org/10.1007/BF00470592

[49] Ikemoto, S., Kohl, R.R. and McBride, W.J. (1997) GABA receptor blockade in the anterior ventral tegmental area increases extracellular levels of dopamine in the nucleus accumbens of rats. Journal of Neurochemistry, 69, 137-143. http://dx.doi.org/10.1046/j.1471-4159.1997.69010137.x

[50] Brodie, M.S., Shefner, S.A. and Dunwiddie, T.V. (1990) Ethanol increases the firing rate of dopamine neurons of the rat ventral tegmental area in vitro. Brain Research, 508, 65-69.

http://dx.doi.org/10.1016/0006-8993(90)91118-Z

[51] Brodie, M.S., Trifunovic, R.D. and Shefner, S.A. (1995) Serotonin potentiates ethanol-induced excitation of ventral tegmental area neurons in brain slices from three different rat strains. Journal of Pharmacology and Experimental Therapeutics, 273, 1139-1146.

[52] Brodie, M.S. and Appel, S.B. (1998) The effects of ethanol on dopaminergic neurons of the ventral tegmental area studied with intracellular recording in brain slices. Alcoholism: Clinical and Experimental Research, 22, 236-244. http://dx.doi.org/10.1111/j.1530-0277.1998.tb03644.x

[53] Brodie, M.S., Pesold, C. and Appel, S.B. (1999) Ethanol directly excites dopaminergic ventral tegmental area reward neurons. Alcoholism: Clinical and Experimental Research, 23, 1848-1852. http://dx.doi.org/10.1111/j.1530-0277.1999.tb04082.x

[54] Bunney, E.B., Appel, S.B. and Brodie, M.S. (2001) Electrophysiological effects of cocaethylene, cocaine, and ethanol on dopaminergic neurons of the ventral tegmental area. Journal of Pharmacology and Experimental Therapeutics, 297, 696-703.

[55] Blaha, C.D., Allen, L.F., Das, S., Inglis, W.L., Latimer, M.P., Vincent, S.R. and Winn, P. (1996) Modulation of dopamine efflux in the nucleus accumbens after cholinergic stimulation of the ventral tegmental area in intact, pedunculopontine tegmental nucleus-lesioned, and laterodorsal tegmental nucleus-lesioned rats. Journal of $\mathrm{Neu}$ roscience, 16, 714-722. 